\title{
Determinants of Capital Resource Productivity in the Enterprise Sector in Vietnam
}

\author{
Dao Thi Bich THUY* \\ VNU University of Economics and Business, Vietnam National University, Hanoi \\ *Corresponding author: thuydaokt@vnu.vn..edu
}

\begin{abstract}
Research purpose:

This paper seeks to address the question of potential determinants for capital resource productivity in the enterprise sector in Vietnam.
\end{abstract}

\section{Research motivation:}

Since 2000, the enterprise sector in Vietnam starts to grow rapidly; however, capital resource productivity is on the declining trend.

\section{Research design, approach and method:}

At the sectoral level, the determinants of capital resource productivity are identified to include the sector's size of capital resource, FDI intensity, industrial agglomeration, type of enterprises by size, size of population and quality of local economic governance. Using the generalized least square method, the empirical study is conducted at the local level with all 63 provinces nationwide in the period from 2006 to 2015.

\section{Main findings:}

Regression findings reveal that the proportion of FDI enterprises, the average size of FDI enterprises, industrial agglomeration, the proportion of large enterprises and the population size all have positive effects on capital resource productivity while the size of capital resource has a negative impact. For the different components that are related to the quality of local economic governance, improvement in informal charges, time costs of regulatory compliance, labor training, land access and tenure security increase capital resource productivity while improvement in entry costs for new firms lowers it.

\section{Practical/managerial implications:}

The implication of these findings calls for the need of attracting FDI to bring in new and advanced technologies, encourage the development of large enterprises, facilitate the formation of industrial zones and parks, effectively implement labor training programs and continuously improve local economic governance.

Keywords: Capital resource, productivity, enterprise sector

\section{INTRODUCTION}

Resource productivity is a measure of the output (expressed either as units produced or as economic value) per unit of resource input [1]. The most common resource productivity is labor productivity that measures how much output that each unit of labor can produce. Determinants of labor productivity include a wide range varying from the macro to the firm levels. At the macro- level, beside the major ones which are capital deepening, human capital and technology, other factors include structure of an economy, government size, financial development, institutional quality, trade openness, income inequality [2] - [5]. Along with labor productivity, another resource productivity is known as capital productivity. The definition of capital is somehow complex. In a narrow term, capital refers to physical capital - structures and equipment - that a firm uses as an 
input in the production process. In a abroad term, capital refers to capital resource which is the firm's entire capital formed from equity and liabilities of the firm. McKinsey Global Institute [6] defines capital productivity as how effectively and efficiently physical capital is employed in the production process. Capital productivity is the ratio of output of goods and services to the input of physical capital. According to OECD definition [7], capital productivity is how efficiently capital is used to generate output. It reflects the joint influence of labor input per unit of capital used and multifactor productivity (MFP). Unlike labor productivity, there is lack of studies on determinants of capital productivity. The study by Morkunaite (2019) found two major factors: capital deepening has a negative effect and TFP growth has a positive effect on capital productivity [8].

Since 1986, Vietnam economy has transformed from centralized economy into socialist oriented market economy. The first Corporate and Private Enterprise Laws 1990 was promulgated and through several times for amendments and supplements the laws created legal corridors for the development of the enterprise sector. The enterprise sector has gradually affirmed its important position in the economy as it is a key sector that creates the economy' output, generates employment and income for workers and is a main source of tax contribution to the government. In 2020, this sector accounts for about $60 \%$ of the country's GDP and contributes more than $80 \%$ of government tax revenue (General Statistic Office of Vietnam GSO). The enterprise sector started growing strongly since 2000 in terms of number of enterprises, the size of capital resource and output generated. During the 2000-2018 period, the number of enterprises grew at an average annual rate of $17.2 \%$. The average annual growth rate of capital resource and of output (adjusted for inflation) was $13 \%$ and $11.7 \%$ respectively. In the year 2018 , the total number of enterprises was about 17 times higher than that in the year 2000. The size of the sector' capital resource (measured in base year 2010 price level) was 8.7 times as much as in 2000 and for the output the number was 7.1 times.

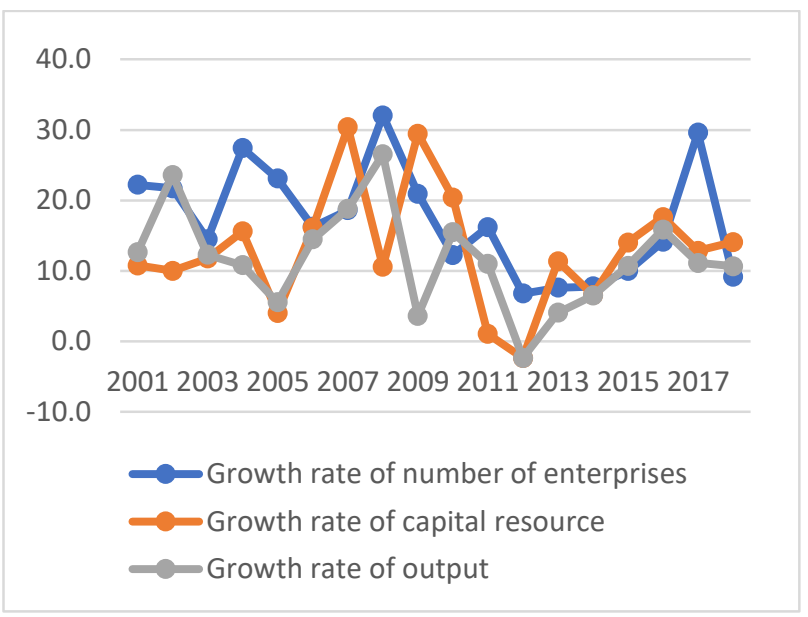

Figure 1. Growth of the enterprise sector in Vietnam

Source: the author own's calculation from the GSO's publications ${ }^{1}$ [9]

From the reported number we can see that on the average, the growth rate of output at $11.7 \%$ is less than the growth rate of capital resource at $13 \%$. This shows a sign of declining in productivity of capital resource. Capital resource productivity is measured by the ratio of sector's output and capital resource which tells how much output can be generated from each unit of capital resource used. Figure 2 shows a trend in capital resource productivity. The productivity of capital resource fluctuated yearly but had a tendency to decline.

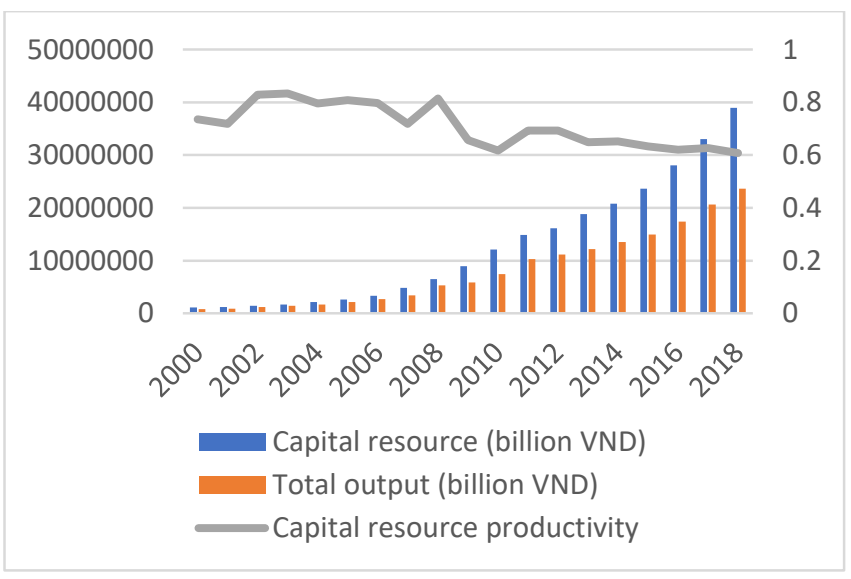

Figure 2. Trend in capital resource productivity

Source: the author own's calculation from the GSO's publications [9]

\footnotetext{
${ }^{1}$ The formular for the annual growth rate of a variable is the percentage change of that variable (i.e. the value of the variable in this year minus the value of the variable in previous year and all divided by the value of the variable in previous year).
} 
Trend in the productivity of capital resource in sectors by types of ownership is presented in Figure 3. The state-owned enterprise sector includes central and local state-owned enterprises. The non-state enterprise sector includes private enterprises, partnerships, private limited liability companies and joint stock corporations. The FDI sector includes $100 \%$ foreign owned enterprises and foreign joint ventures. We can see that the stateowned sector had the lowest productivity of capital resource which implies this sector was the least efficient in capital resource usage. The non-state sector at first had the highest capital resource productivity but from 2009 it was outweighed by the FDI sector. An alarming point is that there was a steady decline in capital resource productivity in this sector. A bright picture is for the FDI sector when it has experienced a rising capital resource productivity and become the sector with highest capital resource productivity since 2009 .

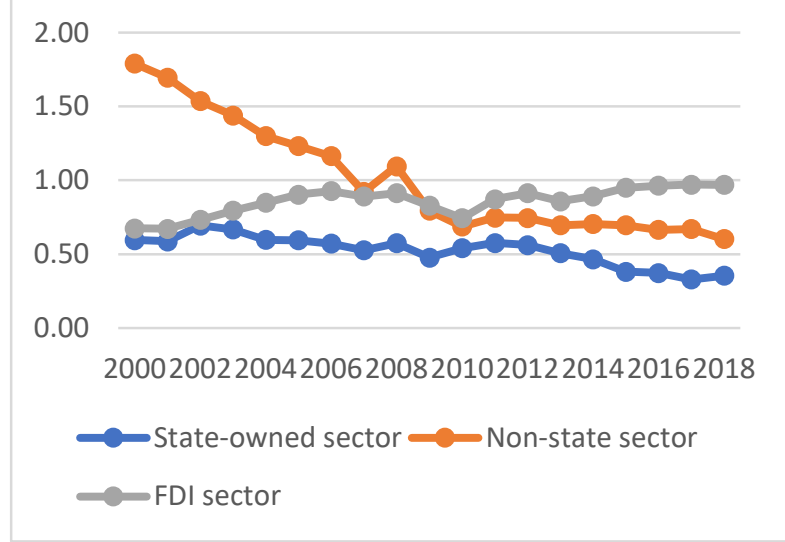

Figure 3. Capital resource productivity in sectors by types of ownership

Source: the author own's calculation from the GSO's publications [9]

What factors affecting capital resource productivity in the enterprise sector in Vietnam? This study aims to find the answer to this question. The organization of the paper is as follows. The next section presents model specification, data and methodology and followed by results and discussion. Finally, is the conclusion.

\section{MODEL SPECIFICATION, DATA AND METHODOLOGY}

Factors determining capital resource productivity in the enterprise sector are identified to include the sector's size of capital resource, FDI intensity, industrial agglomeration, type of enterprises by size, the size of population and quality of local economic governance. The size of capital resource reflects capital deepening and the rest factors account for TFP growth.
First, the size of capital resource is expected to have a negative effect on capital resource productivity due to the law of diminishing returns. To interpret it, the neoclassical production function is given as $Y=A X^{\alpha}$, where $\mathrm{Y}$ is total output, $\mathrm{X}$ is aggregate input involving all inputs which can be employed within the constraint of capital resource and A represents all factors other than inputs that have effect on output which is known as total factor productivity TFP. $\alpha$ is factor intensity which takes the value from 0 to 1 . The marginal product of input is $M P X=\Delta Y / \Delta X=\alpha A X^{\alpha-1}=\alpha(Y / X) \quad$ or input productivity depends on its marginal productivity $(Y / X)=M P X / \alpha$. The first derivative of marginal product of input is negative $\triangle M P X / \Delta X=\alpha(\alpha-$ 1) $A X^{\alpha-2}<0$, which says that other things being constant, as more input is used the marginal product of input decreases and so does with input productivity.

Second, FDI intensity is expected to increase the level of advanced technologies used in the sector. In the form of direct foreign investment, foreign firms bring with them advanced technologies to the host countries and provide an effective channel for technology transfer. Foreign firms can create backward and forward linkages with local firms. With backward linkages, foreign firms rely on domestic firms for their intermediate inputs. In order to meet the in time delivery and quality standard of inputs, foreign firms can assist their local partners with superior technologies as well as inventory management skills. With forward linkages, domestic firms can enjoy high quality inputs supplied by foreign firms at competitive costs. This also saves costs for domestic firms since they do not need to incur transportation costs should the equivalent quality inputs imported from overseas. Besides, the physical existence of foreign firms in the local markets can benefit domestic firms though knowledge diffusion and local labor training. By observation or employment of labor who previously worked in the foreign firms, domestic firms can learn better managerial methods and effective resource management and utilization practiced by foreign firms. Advanced technologies and better managerial methods should increase the sector's resource productivity.

Third, industrial agglomeration refers to the situation when firms belonging to the same industry locate near each other to exploit the external benefit of economies of scale. By clustering in a given geographical area, as the scale of production for the whole group increases, each firm can enjoy a lower per unit cost of production. A high density of firm in a given location attracts pools of skilled labor and specialized input suppliers. As a result, each firm has easy access to employ needed-skill labor and purchase inputs at competitive costs. Cost saving means a higher level output can be produced from each unit of resource used or higher resource productivity. 
Fourth, the type of enterprise by size can decide the effectiveness of resource usage. Large enterprises backed up with large financial capacity can have more motivation in investing in innovation activities than small and medium enterprises. They are likely to come up and apply better technologies than small and medium enterprises. In addition, the fact that the adaptation of an advanced technology usually requires a new chain of production with a huge initial investment. This chain of production once operated has a high production capacity at a low cost per unit. A chain of production like that is only efficient for large enterprises with high scale of production. Therefore, by being large in size, large enterprises can have the advantage of economies of scale over small and medium enterprises and enjoy higher resource productivity.

Fifth, the size of population may affect resource productivity in two ways. Firstly, a large population results in an abundant labor force which gives chance for firms to employ workers with low costs. More labor can be employed and as a result more output can be produced from a given amount of resource. Secondly, a large population also means a big market size which has potential to absorb large output. This would create an incentive for innovation leading to output expansion.

Finally, quality of local economic governance shows the efforts by local government in providing a conducive business environment for the development of business sector. Local economic governance covers a wide range of activities, including granting permissions and licenses; providing services (local infrastructure and services, business development programs, local labor training and resolution of disputes); regulating and monitoring (setting rules/standards that influence business operations and conducting business inspections) and dialogue between government and local business sector (engagement of business community in government decision making when firms can talk to the government and the government can consult them on its plans and proposals). Quality of local economic governance would have a direct effect on the business performance of firms in terms of costs and efficiency of resource usage.

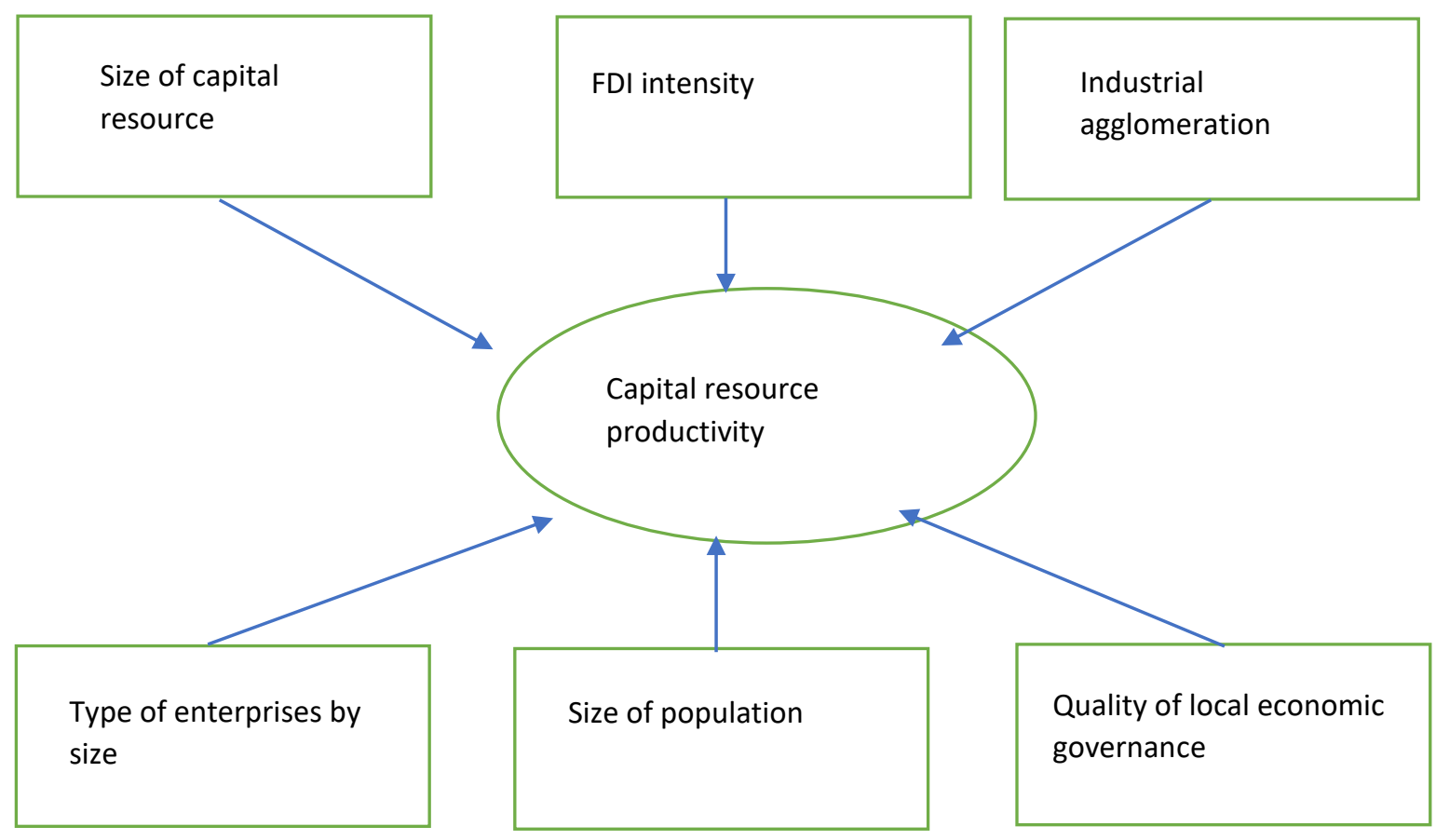

Figure 4. Conceptual framework on determinants of capital resource productivity in the enterprise sector in Vietnam

From the conceptual framework, the regression equation is set up as follows

$$
L N K P_{i, t}=c+\beta_{1} L N K_{i, t}+\beta_{2} S F D I_{i, t}+\beta_{3} L N A F K_{i, t}
$$

$$
\begin{aligned}
& +\beta_{4} L N N E D_{i, t}+\beta_{5} S_{L E} E_{i, t}+\beta_{6} L N P O P_{i, t} \\
& +\sum_{k=1}^{9} \beta_{k_{i, t}} \text { PCIX }_{k_{i, t}}+\alpha_{i}+\mu_{t}+e_{i, t}
\end{aligned}
$$


where subscript $i$ indicates province and subscript $t$ is time in year.

\section{Dependent variable}

Capital resource productivity (LNKP) is the natural logarithm of capital resource productivity. Capital resource productivity is measured as the ratio of the sector's output and capital resource.

\section{Explanatory variables}

Size of capital resource (LNK) is the natural logarithm of the sector's capital resource.

Share in number of FDI enterprises (SFDI) is the ratio of the number of FDI enterprises to the total number of enterprises.

Average size of FDI enterprises (LNAFK) is the natural logarithm of capital resource per foreign enterprise where capital resource per foreign enterprise is measured as the total FDI capital resource divided by the number of FDI enterprises.

Industrial agglomeration (LNNED) is the natural logarithm of density of enterprises with the density of enterprises calculated as the number of enterprises per 1000 inhabitants.

Share of in number of large enterprises (SLE) is the ratio of the number of large enterprises to the total number of enterprises.

Size of population (LNPOP) is the natural logarithm of population where population is the number of inhabitants in each province.

Quality of local economic governance ( $\sum$ PCIX): A proxy measurement for this variable is the Provincial Competitiveness Index (PCI). The nine sub-indices of the PCI are as follows: PCIMK is entry cost for new firms, PCILA is land access and security of tenure, PCITR is transparency, PCITC is time costs of regulatory compliance, PCIIC is informal charges, PCIPL is proactivity of provincial leadership, PCIES is the business support service, PCILT is labor training and PCILR is the legal institutions. Each sub-index is constructed with the maximum score of 1.00 and a higher score reflects a better quality of local economic governance in creating a healthy and favorable business environment.

$\mu_{t}$ is a time specific effect, $\alpha_{i}$ is an unobserved provincespecific fixed effect and $e_{i, t}$ is the error term. The study uses two sets of data. Data for the sector's output and capital resource, FDI capital resource, number of enterprises (FDI, total, large) and population is taken from Statistical Year Book and various surveys on business results published by the GSO [9]. Capital resource is the enterprises' entire capital which is formed from equity and liabilities of the enterprises. The most available data for the sector's output is the sector's total net turnover. Total net turnover is the amount of money businesses earn from the sale of goods and services, investment property, and other revenue minus deductions (trade discounts, sales discounts, goods sales returns) during the reporting period. Data for quality of local economic governance is taken from the PCI which has been jointly developed by the Vietnam Chamber of Commerce and Industry (VCCI) and USAID [10].

The empirical study is conducted at the local level with all 63 provinces nationwide in the period from 2006 to 2015 . The chosen period of study is mainly dictated by the availability of data. Data for the 63 provinces is collected over the same period which forms a strongly-balanced panel data. Regression analysis on panel data requires for the control of unobserved factors affecting the dependent variable. Because each province has its own characteristics, these unobserved factors are regarded as provincial heterogeneity. Regression analysis is performed with Stata program. Various diagnostic tests reveal that there are problems of cross-sectional dependence, serial correlations and heteroskedasticity. With the presence of these problems in data, the generalized least square method is used as suggested by Torres-Reyna (2007) [11]. The regression results are presented in $\quad$ Table 1. 


\section{RESULTS AND DISCUSSION}

Table 1. Determinants of capital resource productivity in the enterprise sector in Vietnam

Dependent variable: LNKP: Capital resource productivity

\begin{tabular}{lcc}
\hline Explanatory variables & Coefficient & P - value \\
\hline LNK: size of capital resource & -0.511 & $0.000^{* * *}$ \\
SFDI: share in number of FDI enterprises & 2.156 & $0.000^{* * *}$ \\
LNAFK: average size of FDI enterprises & 0.106 & $0.000^{* * *}$ \\
LNNED: industrial agglomeration & 0.406 & $0.000^{* * *}$ \\
SLE: share in number of large enterprises & 4.312 & $0.001 * * *$ \\
LNPOP: size of population & 0.601 & $0.000^{* * *}$ \\
PCIMK: entry costs for new firms & -0.498 & $0.028^{* *}$ \\
PCILA: land access and security of tenure & 0.351 & $0.081^{*}$ \\
PCITR: transparency & 0.089 & 0.650 \\
PCITC: time costs of regulatory compliance & 0.499 & $0.004 * * *$ \\
PCIIC: informal charges & 1.380 & $0.000^{* * *}$ \\
PCIPL: proactivity of provincial leadership & -0.017 & 0.903 \\
PCIES: business support service & 0.021 & 0.897 \\
PCILT: labor training & 0.350 & $0.069 *$ \\
PCILR: legal institutions & 0.099 & 0.546 \\
CONSTANT & -1.003 & 0.000 \\
\hline
\end{tabular}

$(* * *): 1 \%$ statistical level of significance, $(* *): 5 \%$ statistical level of significance, $(*): 10 \%$ statistical level of significance. Year dummies are included in the model but not showed in the results.

Source: The author's own calculation (see Appendix).

As can be seen from the results in Table 1, all five determinants of capital resource productivity including the size of capital resource, FDI intensity, industrial agglomeration, share of large enterprises and the size of population show to have an expected sign effect with $1 \%$ statistical level of significance. First, when the size of capital resource increases by $1 \%$, capital resource productivity decreases by $0.51 \%$. This is due to the law of diminishing returns. Second, FDI intensity is measured by the share in number of FDI enterprises and the average size of FDI enterprises. The higher the share in number of FDI enterprises, the more presence the FDI in the sector. Besides, a larger average size of FDI enterprises means a larger investment that each foreign firm makes and thus a deeper involvement of foreign enterprises in the sector. Both variables of FDI intensity have a positive relation with the sector's capital resource productivity. This is a robust evidence that foreign firms create positive spillovers effect on domestic firms that results in an increase in the whole sector's level of capital resource productivity. Positive spillovers can work through the channels of technology transfer, knowledge diffusion and local labor training. Third, higher capital resource productivity is realized when each firm gains external benefit by clustering in given geographical areas. $1 \%$ increase in the density of firms results in $0.41 \%$ increase in capital resource productivity. Fourth, with the coefficient value of 4.31 for the share in number of large enterprises, large enterprises show to be more efficient in capital resource usage than small and medium enterprises. The more number of large enterprises in relation to small and medium enterprises, the higher the level of capital resource productivity in the sector. Fifth, capital resource productivity increases by $0.6 \%$ as a result of $1 \%$ increase in the size of population. That suggests the growth in population increases the size of labor force which makes it easier for firms to get cheap labor. Besides, higher labor force also means a higher chance for firms to employ the needed-skill workers at competitive wages. Cost savings result in higher output produced from a given amount of resource and thus higher capital resource productivity.

For the group of quality of local economic governance, five out of nine explanatory variables have a statistically significant impact on capital resource 
productivity, of which four variables show positive effects and one shows a negative effect. Among the positive effect variables, improvement in informal charges has the highest impact. Informal charges refer to unofficial payment that firms make to provincial officials in the hope of facilitating for their business operation. This is a kind of corruption which can create a great burden on firms especially when they engage in a lobbying race among themselves. Better corruption control can reduce this cost burden and allow firms to direct more resource to output creation activities which results in higher output produced. Come second is the improvement in time costs of regulatory compliance. Time costs of regulatory compliance is a measure of how much time firms spend on bureaucratic compliance and business inspections by local regulatory agencies. Regulatory compliance time in some sense is a wasting time since it drives firm away from production activities. Firms may have to shut down their operations for inspections and thus frequent and unnecessary long inspections can cause a significant loss of output for firms. Improvement in time costs of regulatory compliance would obviously freer time for firms in production activities. Next, labor training has the third positive impact on capital resource productivity. Labor training policies and programs are implemented by provincial authorities to promote vocational training and provide necessary skills for local workers in order to meet the labor requirements of businesses. More efforts provided in labor training result in better skilled workers which increases labor productivity. Higher labor productivity means each unit of capital resource used to employ workers brings in more output generated. Fourth, land access and security of tenure is a measure combining two dimensions of the land problems confronting entrepreneurs: how easy it is to access land and the security of tenure once land is acquired. When enterprises have easier access to land and especially when the risks of tenure are reduced (lower possibility of expropriation, unfair compensation values, or changes in the lease contract) the duration of tenure is guaranteed, they will be assured of long-term development orientation and pursue more effective investment strategies.

Finally, the improvement in entry costs for new firms, unexpectedly, has a negative impact on the capital resource productivity. That is, lower entrant costs for new firms would bring harm to the capital resource productivity. One possible explanation for this is that lower entrant costs would reduce barriers to new firms and make it easier for new firms to enter the markets. Higher competition in the product markets forces up the demand for inputs which put pressure upward on input prices and thus higher costs of production for firms. Higher unit cost of production means less output can be produced from a given amount of resource.

\section{CONCLUSION}

Since 2000, the enterprise sector in Vietnam has experienced steady growth in the size of capital resource and total output. How efficiently capital resource is used to generate output is a measure of capital resource productivity. Capital resource productivity in the sector, however, has fluctuated and showed a tendency to decline. The study attempted to find out factors affecting capital resource productivity in this sector. The determinants of capital resource productivity are identified to include the sector's size of capital resource, FDI intensity, industrial agglomeration, type of enterprises by size, the size of population and quality of local economic governance. Except for the negative effect of the size of capital resource, the other factors positively affect the efficiency of capital resource usage in one of two ways: improvement in productivity of inputs and reduction in costs. Higher input productivity enables firm to produce more output from a given amount of resource while reduction in costs allows firms to purchase more of inputs to produce output.

Advanced technologies, improvement in methods of management and utilization of resource and better skilled labor force can lead to higher input productivity. FDI is considered as an effective channel for technology transfer, knowledge diffusion and local labor training. A positive relation between FDI intensity and capital resource productivity is found. Higher FDI intensity means a stronger presence of foreign firms in relation to domestic firms which helps to foster the technological progress and adaptation of more effective managerial skills in the sector. Besides, large enterprises showed to be more productive than medium and small enterprises since increase in the share of large enterprises has a positive effect on capital resource productivities. Some advanced technologies may be suitable only for large scale production and large enterprises who have large financial potential have more incentive to carry out R\&D and innovation activities as well as engage in advanced training for workers. In terms of quality of local governance, a positive effect of labor training on capital resource productivity implies that labor training policies and programs implemented by provincial government show its effect when it helps to increase the skill level of local workers and thus their labor productivity.

Reduction in costs can be realized in various ways. Firstly, internal economies of scale means that when a firm increases the level of output produced, its 
per unit cost decreases. This cost benefit is the advantage for large enterprises over small and medium ones. A positive relation between the share of large enterprises and capital resource productivity supports this point. Secondly, with the existence of external economies of scale, the per unit cost of each firm decreases when the scale of production by all firms as a group increases. By clustering in a given geographical area, firms can gain external economies of scale. A positive effect of industrial agglomeration on capital resource productivity is found which suggests that the development of industrial zones facilitates the close location of firms and promotes efficiency. Thirdly, large population creates large size of labor force which gives more chance for firms to employ workers at competitive labor cost. Finally, improvement in local economic governance can effectively reduce firms' costs. Improvement in informal charges lowers corruption practices which clearly reduces the cost burden on firms. Improvement in time costs of regulatory compliance would reduce the wasting time and allow firms to spend more time and resource to production activities.

Several policy implications can be drawn from this study. In order to increase the productivity of capital resource in the enterprise sector, local government should provide measures to attract FDI to bring in new and advanced technologies, encourage the development of large enterprises, facilitate the formation of industrial zones and parks and effectively implement labor training programs for local workers. In addition, continuous improvement in local economic governance to provide a conducive business environment is needed.

\section{REFERENCES}

[1] https://proxy.eplanete.net/galleries/broceliande7 /resource-intensity-and-resource-productivity

[2] Dua, P. and Garg, N., 2019. "Determinants of labor productivity: Comparison between developing and developed countries of AsiaPacific". Pacific Economic Review, doi:10.1111/1468-0106.12294.

[3] Alcalá, F. and Ciccone, A., 2004. "Trade and Productivity". The Quarterly Journal of Economics, 119(2), pp.613-646.

[4] Alhaj, E., 2020. "The Determinants of labor productivity in Jordan during the period 19802017'. International Journal of Business and Economics Research, 9(1), 21-28.

[5] Samargandi, N., 2018. "Determinants of labor productivity in MENA countries". Emerging Markets Finance and Trade, 54(5), 1063-1081.
Productivity, Washington. D.C.

[7] OECD: https://www.oecd-ilibrary.org/industryand-services/oecd-compendium-of-productivityindicators-2015/capital-productivity_pdtvy2015-9-en

[8] Morkunaite, K., 2019. "Secular decline in capital productivity in G7 countries". Intereconomics, 54 (6), 385-390.

[9] GSO: Foreign direct investment enterprises in the period of 2006-2011, Results of foreign invested enterprises in the period 2011-2016, Development of Vietnam enterprises in the period of 2006-2011 and Business results of Vietnamese enterprises in the period 2000-2014.

[10] VCCI and USAID: The Provincial Competitiveness Index Reports

[11] Torres-Reyna, O., "Panel data analysis fixed and random effects using Stata", available at https://www.princeton.edu/ otorres/Panel101.pd f, 2007. 


\section{APPENDIX}

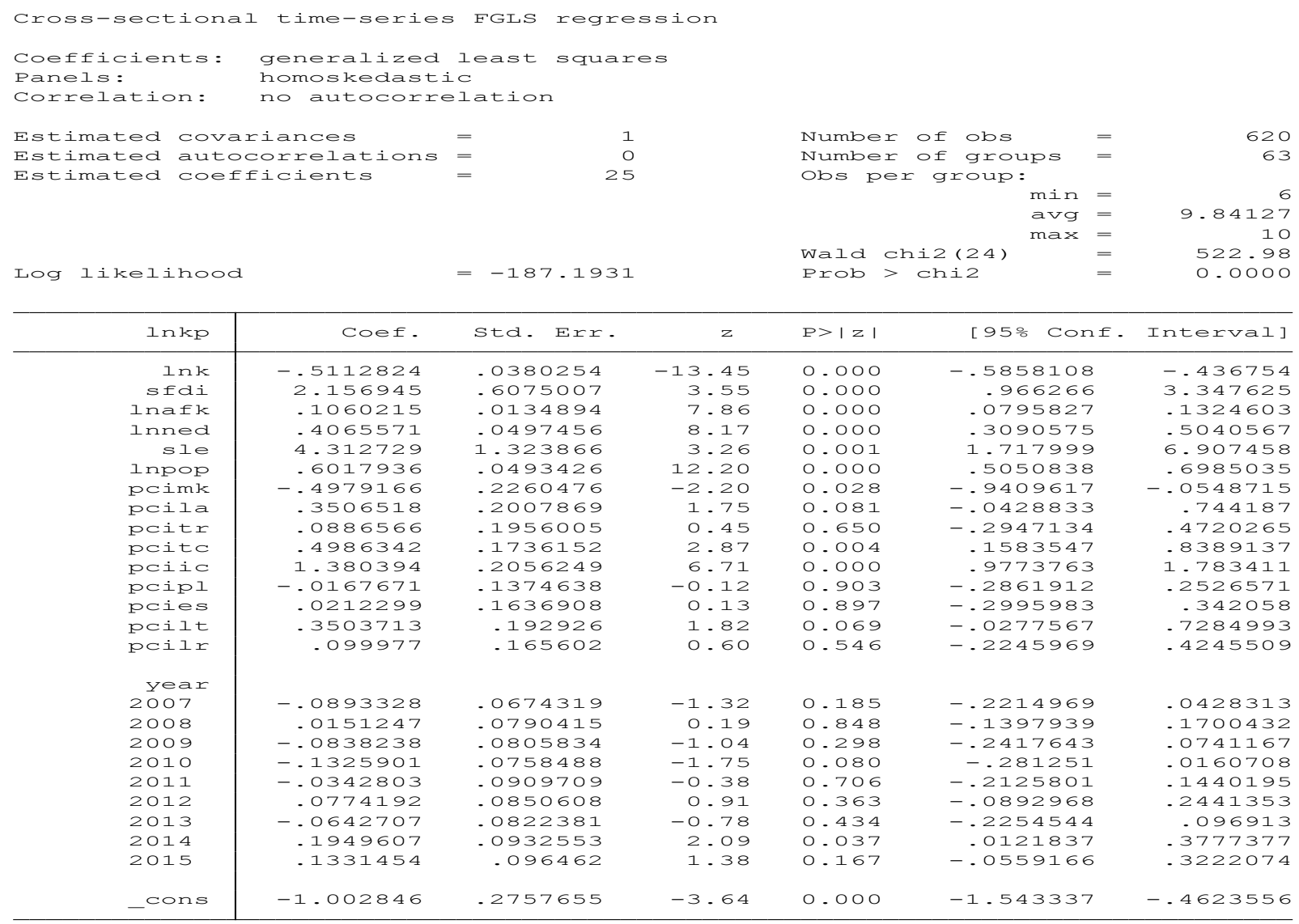

